\title{
SURVEYS
}

\section{Scientific predictions or navel gazing?}

\section{Joseph Mbithi wa Kivilu and Ronnie Mmotlane}

Dr Joseph Mbithi wa Kivilu is director of the Schooling Unit of the Education and Skills Development (ESD) programme of the Human Sciences Research Council (HSRC) e-mail: jmkivulu@hsrc.ac.za

Ronnie Mmotlane is a researcher in the Schooling Unit of the Education and Skills Development programme of the HSRC

\begin{abstract}
Pre-election surveys to predict election outcomes have produced inconsistent results because different researchers or research organisations apply different methodologies and research designs even when dealing with the same subject. The object of this article is to interrogate the nature of survey research as a scientific tool in general and to trace the development of its use in political and government settings, especially in South Africa, to predict election results. The study strives to establish whether or not some pre-election surveys in South Africa rely on inadequate methodology, or else succumb to political pressure to produce predictions that favour a certain party? Attention is directed to issues of reliability and the validity of survey results that can predict the outcomes of elections with a high degree of accuracy. We examine the extent to which different survey organisations and researchers heed the prerequisites and demands of scientific methods in research and, more especially, the methodologies used in surveys. Examining results produced by various research organisations we explore whether political surveys today are adequate tools to predict scientifically outcomes in an election or whether they are simply mechanisms used to arrive at desired goals at the expense of scientific methods. Common flaws in methodologies used to make predictions are identified and discussed.
\end{abstract}

\section{INTRODUCTION}

It is important for different research surveys to produce consistent results that predict sound pre-election outcomes. This is because different researchers 
or research organisations apply different methodologies and designs even when dealing with the same subject. While some draw and weight accurately representative samples that present a valid picture of the population and its demographic variability some may be said to bias their methodologies, either by neglecting real variability in complex populations such as that of South Africa or by purposely designing their surveys to meet their assumptions about certain political parties.

This article interrogates the nature of surveys as a scientific tool and traces the development of their use in political and government settings, especially their recent application in South Africa. The study strives to establish whether some surveys in South Africa rely on inadequate methodology or succumb to political pressure to produce predictions that please the dominant party? South Africa's multicultural society and its history of socio-economic inequalities contribute to uneven results in some surveys. The results of methodological bias are high in multicultural societies such as those in South Africa and the United States. For example, the 1936 poll conducted by the Literary Digest in the United States erroneously predicted an election victory for Alf Landon over Franklin Roosevelt, mainly because the investigators biased their survey by over-representing Landon's supporters and received a sloppy response rate from the sample (Squire 1988; Weisberg, Krosnick \& Bowen 1996; Crossen 2006).

This type of error bias in pre-election surveys confirms some of the general disadvantages not only of survey methodologies in the political polling field but also of most of the research methods used or preferred by researchers in other research fields. In South Africa particularly surveys have - as the Literary Digest did some 50 years ago - committed the bias of over representing people from the middle class and those with access to telephones, while neglecting the majority (Idasa 2006; Franklin 2003; Squire 1988). For this reason this article further explores the extent to which different survey organisations and researchers pay attention to the prerequisites and demands of scientific research methods, especially methodologies, in conducting their surveys.

Although political polls are intended to collect quantitative information on the views or attitudes of potential voters in order to predict the outcomes of an election they share some common flaws with other types of surveys, such as those used in the broader social sciences. In general, surveys depend on the subjects' motivation, honesty, memory, and ability to respond (Caplan 2002). Accordingly, respondents are not motivated to give accurate answers in all settings. For example, it may be hard for participants to recall information or to tell the truth when answering a controversial question (Palmquist 2005). Most surveys' weaknesses contribute to their unevenness, thus, when predicting possible outcomes of an election it is important to acknowledge factors that 
influence the behaviour of the respondents and not merely to probe the survey methods.

With South Africa at the apex of its democratic consciousness the need and use of political surveys to predict election outcomes is on the rise. Since 1994 South African research and media organisations such as the Institute for Democracy in South Africa (Idasa), the Human Sciences Research Council (HSRC), Ipsos Markinor, and The Star newspaper, among others have conducted pre-election surveys that have sought, among other things, to uncover people's voting intentions and their attitudes to democracy, economic evaluations and other political issues (Mattes, Gouws, James \& Kotze 1994). However, prior to the 2009 national and provincial elections most of these research surveys released inconsistent results about the outcomes. According to Schulz-Herzenberg (2009, p 1) 'public opinion polls in the months prior to elections were often a source of contestation, as they returned contradictory results and analysts could not easily make sense of voter intentions'.

Although the South African Institute of Race Relations (SAIRR) predicted that the African National Congress (ANC) was likely to accumulate less than 66 per cent of the votes, the organisation's overall forecast in 2009 was not significantly accurate when compared to the results (Cronje 2009). The results produced by other research organisations, such as the HSRC and Ipsos Markinor, were also inconsistent. These errors not only put South African pre-election surveys at risk because of uncontrollable quantities of uneven survey data, they also put in doubt the validity and reliability of political surveys in South Africa in general.

The inconsistent results may be the result of research organisations using different methodologies in making their predictions and may also call into question the ways in which the research organizations and the IEC compute the percentage of votes cast for a particular political party. There is no consensus on whether computations should be based on the number of registered voters or on the number of voters who actually vote.

Pre-election surveys have general disadvantages that may affect all who use them, and these may differ from survey to survey depending on the political setting of a particular country. Truman (1951) found that election prediction surveys based on forced-choice scales had a higher degree of error than those that used subjective or open scales. He further found that subjective scales could only introduce errors in political settings where more than two candidates or parties were involved in an election. Survey researchers tend to use different scales without paying attention to the influence they may have on the final results. The pressure of conducting pre-poll surveys and producing the results within a short time does not allow enough time for researchers to interrogate the validity of the measuring scales they choose to apply. Smith (1987, p 595) asserts that 
most public opinion surveys have a narrow focus and share common features with omnibus surveys. This raises the question of whether political surveys are adequate tools today for scientifically predicting election outcomes or whether they are simply mechanisms used to arrive at desired goals at the expense of scientific methods.

\section{THE NATURE OF SURVEYS}

According to Idasa (2006, p 1), surveys are 'methods of gathering information from a sample of individuals within a particular group or population'. Although it might be difficult to point to the year in which the first survey was used it is generally understood that the use of surveys as professional tools for gathering and measuring information began in the first half of the $19^{\text {th }}$ century, with pre-poll surveys such as Gallup and the Literary Digest gaining popularity as effective scientific predictors of potential election winners in the United States (Smith 1987; Squire 1988).

It is because of the fallacies arising out of some of these studies that researchers like Parry \& Crossely (1950) first raised general questions about the validity of surveys. For example, Parry \& Crossely (1950, p 66) noted that there 'seemed to be less concern with the more vital matter of validity as representation of truth' in popular government surveys, while Adcock \& Collier (2001) and Clausen (1968) have noted that despite the advances in political science methods, little attention has been paid to measuring validity.

As Rymarch (www.socialresearchmethods.net/tutorial/Rymarchk/rymar2. $\mathrm{htm}$ ) has noted, the difficulty of using any method to measure a phenomenon of social science is that you never know for certain whether you are measuring what you want to measure. In this case, validity is an adequate test tool to determine whether a researcher measures what he or she desires to measure. Despite these concerns, many organisations and individuals in different fields continue to use surveys to gather information or draw conclusions about particular groups, or even to compare and measure people's opinions about and attitudes to certain products, as is the case in market research.

\section{THE HISTORY AND APPLICATION OF SURVEYS IN SOUTH AFRICA, 1994-2009}

The use and application of surveys in South Africa cannot be separated from the country's political history. Even prior to the existence of the apartheid political system South Africa was largely a divided society. It was only in the 1970s that the first pre-election poll was cast among white South Africans by the Argus Group 
and Dagbreek newspapers (Seekings 1997). Seekings (1997, p 288) cites concerns that might have helped to build the culture of biased pre-election prediction as 'a neglect of explicit analysis of voting behaviour' and comments on 'the primacy of racial and ethnic groups that have been taken for granted'. According to Seekings (1997) a thorough analysis of voting behaviour would have required the use of survey data about individual attitudes rather than merely aggregated election results. The problem is further exacerbated by delays in political polling in South Africa as compared to Britain and America, the two countries on which it has consistently modelled its electoral system.

Discrepancies first appeared in the early 1900s when the franchise excluded black South Africans and women from voting. For example, despite the South African Act of 1909, which unified the self-governing British colonies and the inland provinces, no provision whatsoever was made for the eventual extension of the franchise to all adult citizens irrespective of race and gender (electionresources. org/za/system/). Although the South African Population Census in the 1980s was enumerated according to the place where persons were located during the census, the census itself did not accommodate all those persons who were not present within the peripheries of South Africa on census night (that is, midnight, between 6 and 7 May 1980). This methodological preference did not give a true picture of the population, even within segregated boundaries. It was, by its nature, a product of the political reality of the time and part of the development of biased surveys in line with the government's needs at the time.

The government, representing minority whites in South Africa during the apartheid years, monopolised and manipulated political institutions, which conducted surveys to favour it. Government institutions that conducted surveys during the apartheid period included the HSRC, Statistics South Africa and other institutions related to producing professional information for the state. For example, White (1992) reports Cloete, Muller and Orkin's construct of the HSRC's history as consisting of changes designed to legitimate the reform initiatives of PW Botha by 'providing scientific knowledge or evidence in support of the social programme'. Most privately-owned research organisations that conduct political opinion surveys are fairly small companies that specialise in designing the questionnaire to be used, tabulating the answers, analysing the meaning of the tabulations and reporting the results to the study sponsor. But they too sought information with regard to methodology and other specialised techniques such as sampling from public institutions such as Statistics South Africa and the HSRC.

Political opinion surveys were extensively used in 1994 (Seekings 1997) and Southall (1994, p 637) reports on the study of methodologies, motivations, shortcomings and results of various opinion polls undertaken between 1990 and 1994 and how they affected party strategies during the negotiations that preceded 
the first democratic elections. Few could legitimately claim to have overcome the numerous difficulties associated with polling most of the African segments of the electorate and the result was both over and under estimates of the level of support for particular parties. Among the methodological problems were the fact that few Africans had telephones and that communities were not easily accessible because of the political violence of the time. Moreover, it was costly for researchers to reach the more remote rural areas (Southall 1994). The result was false predictions by many researchers about the 1994 elections.

The HSRC, for instance, was completely wrong, predicting that 67 per cent of voters would vote for the ANC, 17 per cent for the National Party (NP) and 6 per cent for the Inkatha Freedom Party (IFP) (Southall 1994, p 637). In fact, the ANC won 63 per cent of the votes, the NP 20 percent and the IFP 10 per cent (see Table 1).

Table 1

HSRC prediction and the results announced by the IEC in 1994

\begin{tabular}{|l|c|c|}
\hline Party & HSRC & IEC results \\
\hline ANC & $67 \%$ & $62.6 \%$ \\
\hline NP & $17 \%$ & $20.4 \%$ \\
\hline IFP & $6 \%$ & $10.4 \%$ \\
\hline
\end{tabular}

Source: Sunday Times 8 May 1994 (Southall 1994)

The challenges for pre-poll predictions in the pre-1994 era included not only poor methodology and unsound assumptions about party support but also inaccurate registration figures and assumed population size.

The methodological problems persisted in relation to later elections. For example, the Afrobarometer Survey of 2008 found that support for the ANC had declined, with only 52 per cent of respondents indicating that they would vote for the party if elections were to be held the following day (Sylvester 2009). Table 2 summarises the results forecast by various survey organisations compared to the actual results announced by the IEC.

An analysis of Table 2 shows inconsistencies among the research organisations, with some predicting the results accurately and others completely missing the mark. There was, however, a shared inconsistency in predicting the results of the larger parties like the ANC and the DA. Schulz-Herzenberg (2009) noted that Afrobarometer, the HSRC, Ipsos Markinor and Plus 94 predicted support for the ANC in the 2009 as 45 per cent, 47 per cent, 61 per cent and 65 per cent respectively. 
Table 2

\section{Predicted vs actual results}

\begin{tabular}{|l|c|c|c|c|}
\hline \multirow{2}{*}{ Survey organisation } & \multicolumn{4}{|c|}{ Political party } \\
\cline { 2 - 5 } & Year & ANC & DA* NNP** $^{*}$ & Cope*** $^{*}$ \\
\hline HSRC & 1999 & & & \\
\hline & 2004 & 67.8 & 10.5 & \\
\hline Plus 94 Research & 2009 & 47.0 & 7.0 & 3.0 \\
\hline & 1999 & & & \\
\hline & 2004 & & & 15.0 \\
\hline Ipsos Markinor & 2009 & 61.0 & 16.0 & \\
\hline & 1999 & 64.7 & 9.5 & \\
\hline & 2004 & 68.0 & 12.0 & \\
\hline Markdata & 2009 & 64.0 & 10.8 & \\
\hline & 1999 & & & \\
\hline & 2004 & 73.7 & 11.2 & \\
\hline IEC Actual & 2009 & 70.5 & 20.6 & \\
\hline & 1999 & 66.3 & 9.0 & \\
\hline & 2004 & 70.0 & 12.0 & \\
\hline
\end{tabular}

Sources: SASAS (2003); Eisa (2009); IEC (2009)

*Democratic Alliance; ${ }^{* *}$ New National Party; ${ }^{* * *}$ Congress of the People

Only two were close to the mark - in fact the ruling party won 65 per cent of the vote. The predictions about the smaller parties were more consistent, as demonstrated by the newly formed Congress of the People (Cope) which, they correctly predicted, would steal the limelight from the existing smaller parties.

\section{HOW CAN PREDICTION SURVEYS BE IMPROVED?}

Political leaders, policy makers, journalists and social researchers have shown a consistent distrust of survey results. For example, South African President Jacob Zuma has laughed off the Ipsos Markinor polls, saying they have always been off the mark (SABC 2009, February). The truth is that most predictive surveys, irrespective of the size of the organisation that commissions them, are neither reliable nor valid nor realistic in their projections.

Weissberg (2001) attributes their flaws to their inherent propensity to measure the wishes and desires of respondents and to the fact that they have little to do 
with direct policy. Although he agrees that surveys are important as they provide scientific means to a political debate, he acknowledges that the answers may be interpreted as responses to the 'wishes' of respondents.

Lynn \& Jowell (1996), on the other hand, believe measurement errors are responsible for the flaws in most surveys. For example, analysing the methodological errors of the 1992 Market Research Society (MRS) report on the underestimation of support for the British Conservative Party Lynn \& Jowell (1996) found that the main factors contributing to prediction errors in the 1992 polls were late swing (people switching their choices immediately before casting a vote), a disproportionate number of people who refused to reveal their voting intentions and inadequacies in the quota variables used (resulting in sampling bias).

After analysing flaws involving sampling errors, response bias and other sources of errors in many election surveys, Lynn \& Jowell (1996) suggest that a high quality two-stage clustered probability sample of 2000-3000 voters be selected from the voters' roll. If this strategy were used only registered voters would be included in the survey, thus ruling out selection bias and improving and minimising sampling bias. They suggest that the use of probability sampling other than quota sampling reduces selection bias. It is recommended that fieldwork be carried out for no more than four days so that the response rate is modest. Most of the suggestions centre on improving and eliminating bias in surveys.

Exit polls, polls of voters taken immediately after they have left the polling station, are another type of survey used to predict election results. Unlike opinion polls, which ask for whom the respondent intends to vote (or some similar formulation) an exit poll asks for whom the voter actually voted. A similar poll conducted before voters have voted is called an entrance poll. The difference is that opinions polls make an appeal for predictability and are liked by many researchers because they promote debate and curiosity. The next sections deal largely with suggestions of how to improve on the accuracy of election polls or surveys.

\section{SURVEYS AS SCIENTIFIC PREDICTION TOOLS}

Inaccuracies in survey results may stem from many factors, including the failure of the survey to be in line with changes in the political landscape that may, to some extent, have affected the attitudes and opinions of the public (Idasa 2006). Factors that concern the application of surveys themselves include faults and biases that may be present during the research design, sampling, and data collection.

Most methodological faults involve errors and bias in the methods themselves: sampling error, data collection methods, question design, language, response error and others (Idasa 2006). Researchers who do not include sufficient respondents in their sample may affect their surveys by acquiring low response 
rates, for example, by using online surveys for populations that may not have access to the Internet or to basic computers (Idasa 2006).

One effective way to determine whether surveys have abided by the scientific rules is to test for validity and reliability (Litwin, 1995; Schulz-Herzenberg 2009). What is more crucial to guarantee that surveys sustain their scientific nature is the extent to which they measure what they intend to measure. Alongside the question of validity are questions involving reliability, objectivity, errors of measurement and sampling errors. Other issues that may lead to errors include data-collection methods, for example, telephone or postal, interviews, questionnaires, household based surveys and random selection of people in cities and villages used by different research organisations. There are many methods and designs that may influence the accuracy of prediction polls, and each may be applied differently according to the specific context or nature of what is being studied.

\section{VALIDITY OF SURVEY RESULTS}

According to Palmquist (2005) validity in surveys is of greater concern to researchers than reliability. Testing for validity is even more crucial in pre-election surveys where predictive and response validity plays a major role in determining the accuracy of survey methodologies in providing forecast outcomes. According to Cronbach (cited in Crocker \& Algina 1986; Kane 2008) validation is the process by which a researcher collects evidence to support the types of inferences that are to be drawn from test scores. This literally means that validity ensures that test providers support what they aim to test. As Adcock \& Collier (2001) maintain, validity also concerns linking ideas, as concepts developed by researchers with facts, as is the case in ecological validity measures. A number of researchers and theorists (eg, Worthen, Borg \& White 1993; Crocker \& Algina 1986; Palmquist 2005) concur that validity can be checked in four different ways:

- Face validity, or to what extent does a survey appear to be able to measure what it is supposed to measure.

- Content validity, or to what extent do the items in a survey represent the content it needs to measure.

- Criterion-related validity, or the extent to which it may be concluded from an individual's score how well he or she is likely to perform on some other task measured by the same test.

- Construct validity, or an agreement between a theoretical concept and a specific measuring device, such as an observation. 
Validity is broader and becomes more complex when internal and external validity types are introduced to define the kind of validity concerned. Hernon \& Schwartz (2009) describe external validity as the extent to which findings are generalisable to a population, while internal validity is the extent to which the research has interpreted the findings correctly or whether or not other factors or variables have been included in the study. Validity measures, like reliability measures, apply to both qualitative and quantitative research designs such as choice of instrument designs and methodologies such as data collection and sampling methods (Adcock \& Collier 2001). However, to determine whether a survey is able to predict the outcomes of the pre-election poll one would, by default, seek to test the validity of the scales used, concentrating on the accuracy, response validity, and contextual specificity of the scales.

\section{Testing for predictability and accuracy}

Testing for predictive validity in survey results is a 'valid' approach to determining how scientific the survey is. Predictive validity is the measure of validity where the construct or attribute being investigated is correlated with some behaviour that occurs at a later point (www.Psychlab1.hanover.edu/Classes/Research/ Terms.html). This type of validity forms part of the criterion-related validation procedure and aims to test the ability of the measure to predict something it should theoretically be able to predict, or how well it can predict or estimate future performance on some valued criterion other than the test itself (Crocker \& Algina 1986; Worthen, Borg \& White 1993; Trochim 2006). This means that if we were to scrutinise the degree to which the measure can accurately predict the outcome we would be testing for the measure's predictive accuracy.

Diebold \& Kilian (2001, p 157) note that 'it is natural and informative to judge forecasts or outcomes by their accuracy'. It is no surprise that Parry \& Crossely (1950) have associated predictive validity with predictive accuracy, while recently Moskowitz \& Pepe (2004) have advanced the science of predictive accuracy by providing prognostic factors as possible indices to help predict unknown outcomes. Furthermore, developments in validation testing of measures have necessitated testing for reliability in predictive accuracy tests; that is, the coefficient between the predictor variable $(X)$ and criterion $(Y)$ needs to be determined. For example, in regression analysis, the goal is to find the line that best estimates or predicts the outcome of a $\mathrm{Y}$ variable (changes in dependent variable) from $X$ (when independent variable is manipulated or varied) that is, the standard error of estimate or a measure of the accuracy of predictions made with this regression line. Reliability, sampling errors, response errors, and methodological errors all affect the extent to which the measure will be accurate. 


\section{Contextual specificity in research}

According to Adcock \& Collier (2001) contextual specificity is the concern with differences in context that can affect the validity of a measurement. They assert that the same score on a measured indicator may yield different meanings in different contexts. In this way, care is taken with the type of population researchers choose to include in a survey. Because there are different cultures within a single population the items included in the measurement tools must be scrutinised and specified to suit particular subgroups. However, theorists, researchers and research organisations have had problems with understanding culture, let alone its measurement and conceptualisation.

While the social identity theory has long suggested that each individual is influenced by a plethora of cultures and subcultures - some ethnic, some national and some organisational - culture has also been conceptualised as a single, unified and universal concept with which specific groups identify themselves. There is an assumption that an individual living in a particular place at a particular time belongs to a single culture; a problem that leads to reduced variance in predictive models (Goliath 2002). It remains a challenge to survey researchers to build into their predictive models the diversity in culture as it exists in South Africa.

\section{RELIABILITY OF SURVEY RESULTS}

Reliability means 'repeatability' or 'consistency'. A measure is considered reliable if it gives the same result over and over again (Trochim 2006). Surveys are reliable if they are consistent, that is, if their applications yield consistent results on several occasions. Reliability in surveys is affected by the inconsistencies caused by random errors. According to Adcock \& Collier (2001) random errors occur when the repeated measurement procedures yield inconsistent results.

Exell (2001) considers random errors to be changes that occur either at the environmental level or as a result of an unreliable measuring instrument. At the environmental level changes leading to errors in surveys procedures include unexpected real life changes involving, among others, changes in political cycles, changes in economic conditions or changes in the political views of respondents. Other differences may arise from sampling. For example, the sampling techniques of pre-poll surveys are not normally census designs, compared to the South African Electoral Commission's policy of an 'all eligible voters' design, meaning that there is a high chance that the sample survey may involve people who are not eligible to vote. Samples of the pre-polls seldom assimilate the overall population of actual voters. 
Random errors at the measurement level involve measurement error (Adcock \& Collier 2001). This means that the measuring instrument used by pre-poll surveys lacks the strength to yield similar results when repeated over time. This could be vital in the sense that survey items in an instrument are different from the simplified items found in a ballot paper. Ballot papers don't ask questions, the nature of which respondents may find demanding in pre-poll surveys. In his critique of the new polling methods Sullivan (2009) found that Internet respondents who are surveyed multiple times per week on different topics develop survey fatigue as they pursue prizes like tote bags, gift certificates, T-shirts and even cash. Though studies on ballot design (eg, Kimball \& Kropf 2005; Denver, Johns \& Carman 2009) have attempted, using survey theories, to investigate the features of ballot designs and their impact on voting errors the issue still rests on the reliability of the method and measures. Exceptions are when there are similarities between the designs of ballot papers and of surveys.

\section{SURVEY METHODOLOGIES}

\section{Sampling}

With regard to sampling techniques Mugo $(2002, \mathrm{p} 1)$ cautions that although 'it is cheaper to observe a part rather than its whole, we should prepare ourselves to cope with the dangers of using them'. What Mugo warns about is the complexity surrounding the dynamics in human populations and the laws guiding demographic profiling and distributions in research surveys. According to Mostert, Hofmeyr, Oosthuizen \& Van Zyl (1998) populations are complex and susceptible to change caused by processes of mortality, fertility and migration and such complexities and changes in populations also affect sampling and how it should go about calculating sampling error and applying valid sampling techniques. This is true, considering the outcomes of important estimations about people in diverse populations. From the early days of surveys sampling has been a major problem as it affects the outcome. Noticeable pitfalls normally range from the creation of sampling frames from available census data to distributing such data randomly across all sectors representatively.

Many surveys are culpable of producing inadequate results if they prove to be poor and show bias in important aspects of research such as response rate, geographical/sample coverage (coverage error resulting from poor random sampling or exclusion of other important people from sampling frame), under-sampling and over-sampling, measurement bias (or unreliable tools of measurement) and social desirability (or the bias of researchers for reasons other than the objective of the survey) among other problems. 
Other survey research biases occur in conjunction with this, for example, the way a survey is conducted, the way questions are itemised and asked, the state of the survey respondent, the reliability and validity of measures and the form in which the language appears or in the manner in which it is used in the testing tool. More specifically, there is frequently bias when the survey sample does not truly represent the population. In that case the sample may be deemed inaccurate or invalid and non-dependable or unreliable. This is because it is crucial for a sample to define and represent accurately the total of the population that is left out of the study (Guy, Edgley, Arafat \& Allen 1987).

Different research organisations apply different sampling methods and techniques. Although the choice of the sampling method or technique may yield particular results, the quality and accuracy of results desired for specific research study depend on the harmony between the objectives of the study and its actual design. Just as there is agreement between the research design and procedures of collecting data, there is also agreement between the design of the study and the type of sampling. For example, in most cases surveys are designed for large statistical groups in which sampling procedures can either be a census, crosssectional or even longitudinal design.

Surveys, like many other research designs, have special sampling procedures valid for desired results. Surveys mainly apply sampling procedures that define statistical groups that are independent from their natural settings and, because of the high need for representivity, surveys take the direction of probability sampling procedures (Guy, Edgley, Arafat \& Allen 1987) which include simple random sampling, clustered sampling and stratified sampling techniques.

Large research organisations such as the HSRC, MarkData, Ipsos Markinor and many others use different sampling techniques to conduct their pre-poll surveys and their results are seldom consistent with the actual electoral results, mainly because of sampling flaws.

Guy and his colleagues (1987) have noted an important factor with regard to opinion polls - organisations rarely make use of a total population when conducting their polls. Consequently, the results obtained by most South African pollsters are inconsistent with those of the IEC. Whereas the electorate is national and equivalent to a census in all respects, most pollsters sample inaccurately in their attempt to predict results. There may also be inconsistency among the pollsters themselves: some sample those actually registered to vote and who are going to the polls on election day, others falsely assume that all citizens are eligible to vote, without confirming their voter status and willingness to vote. Still other organisations base their assumption on voter turnout. Below is the summary of sampling procedures different research organisations in South Africa construct for pre-poll surveys: 


\section{Mark Data}

Mark Data uses an Omnibus survey based on a multi-stage stratified probability sample of 2300 adult South Africans living in all types of residential circumstances from deep rural traditional areas to small towns and large cities, including suburban residential areas, flats, townships, informal areas, hostels and commercial farming areas. For specific pre-poll surveys Mark Data utilises a simple random sampling technique targeting potential voters on a data collection method called a 'secret ballot' to trace their voting preferences and to determine their willingness to vote. Like many research organisations Mark Data prefers face-to-face interviews conducted in the home language of the respondent and employs and trains fieldworkers to carry out the interviews. In the pre-election analysis in 2004 Mark Data excluded from their results all respondents who indicated that they would either 'not vote' or were 'very unlikely to vote'. Respondents who were uncertain about which party they would support (which, in their analysis, constituted about $20 \%$ of the sample) were categorised on the basis of other questions, including their rating of the major parties and their leaders. The predictions of the 2004 election pre-polls were based on the assumption of a fairly high turnout.

\section{Ipsos Markinor}

Ipsos Markinor conducts independent and autonomous socio-political surveys biannually, with additional surveys in election years. A standard sample size of 3500 respondents is used. Like many research organisations Ipsos Markinor strives for representivity; respondents who are representative of the entire adult South African population. Like Mark Data Ipsos Markinor offers Omnibus surveys in pre-polls, but goes further, using data collection methods encompassing, firstly, the household type of face-to-face interviews (or what they call the 'Khayabus') and secondly the computerised form of telephonic interview (the 'Telebus'). The Khayabus includes selected cities in Gauteng (ie, in districts of the West Rand, the East Rand, the Vaal, Pretoria and Johannesburg), Durban, Pietermaritzburg, Bloemfontein, Welkom, Port Elizabeth, East London and Cape Town. It also includes non-metro districts in all nine provinces, including deep rural areas. The Telebus uses 88 stations in six centres across the country and, like the Khayabus, also includes cities and towns (brandsandbranding-online.co.za/images/brand_ profiles/09_Profiles/Ipsos.pdf).

\section{HSRC}

The HSRC's pre-poll survey is drawn from the set of questions in the HSRC's South African Social Attitude Survey (SASAS). SASAS draws on a representative sample of about 5734 South Africans aged 16+ years from the HSRC Master Sample. The sample is stratified by the sociodemographic domains of province, geographical 
subtype and the four population groups. This is done mainly through household face-to-face interviews, using trained fieldworkers combined with the advanced geographic information systems (GIS) (Pillay, Roberts \& Rule, 2006).

\section{TOTAL SURVEY ERROR}

One of the most important aspects to bear in mind when projecting or drawing conclusions from surveys is the issue of total survey errors (TSEs), or the interactions between many sources of errors in the survey. TSEs include sampling error, coverage error, measurement error, and non-response error. Editing and processing errors - errors in estimates derived from survey data - are vital in interpreting research results and are important in determining the outcomes of research surveys. TSEs can be both systematic and random. They can be identified as systematic error when the cause or source of the error is known or could be predicted as bias resulting mainly from the measurement instrument (Adcock \& Collier 2001; Exell 2001; Litwin 1995). Random errors are unpredictable and usually unknown. The goal of research is to minimise the degree of TSEs in surveys.

Researchers quantify sampling error to understand how much the results of the sample may differ because of chance when compared to what would have been found in the entire population. In preparing for surveys whose outcomes would be generalisable to the target population, those conducted by large research houses, in particular the HSRC in the social sciences, Statistics South Africa in demographics, Ipsos Markinor in economics, and the Medical Research Council (MRC) in medical sciences, take steps to boost the confidence level of their research results by calculating the margin of error. In reporting on the accuracy of results the HSRC states the confidence interval of 95 per cent of accounted margin of error, thus accounting for only a \pm 5 per cent of error agreeable within the social sciences (www.comfsm.fm/ dleeling/statistics/notes010.html).

Despite the allowance made for such systematic error there is also the possibility of a random error in survey sampling. One of the sources of such error is selection bias. Similar to coverage error, selection bias is motivated by researchers who draw samples without considering all the angles of demographics in the population. Selection bias is common, though not limited to, non-paper/nonface-to-face methods like Internet, telephone, cellphones and e-mail. An example of selection bias was identified in the recent American elections where YouGov/ Polimetrix's polling showed that John McCain would win the state of Indiana by eight points. In fact, Barack Obama won the state by nearly one percentage point $(0.9 \%)$ (Sullivan 2009). YouGov / Polimetrix sampled respondents who had agreed to be a part of their sample pool in the past and had neglected to update the pool. 
The goal of non-response error is to minimise error by collecting data on all members of the sample. Bias, in this case, is the failure of surveys to predict accurate outcomes compatible with an election sample. This is the proportion of responses drawn at random from the population who actually participate in a survey reflecting the views of the population interviewed (Global Market Insite Inc - GMI 2010). The main cause of this error is the method used for collecting data. For example, researchers may opt to draw their data using Internet surveys from a number of people in areas with low Internet access. It is most likely that the Internet or telephonic response turnout in villages is lower than in metropolitan areas, where a significant number of people have access to computers.

The tendency to use electronic devices instead of traditional paper survey designs is one of the leading factors in measurement bias and error. For example, in its defence of mobile surveys, Mobile Researcher, a software-as-a-service company (www.populi.net/mobileresearcher/) has argued that without a dedicated survey design tool that asks questions consistently and if the logic is not described clearly to the fieldworker, outcomes can vary significantly.

It has analysed problems faced by paper surveys as involving issues of fieldworker bias, fatigue, misinterpretation of question items, influence to responses and localised terminology, among others, and has judged the design process that involves multiple stakeholders in research as resulting in inaccurate survey outcomes (www.community.populi.net/mobileresearcher/index. $\mathrm{php} /$ 2010/03/ paper-versus-mobile-data-collection/). Lindner and Wingenbach (cited in Wiseman 2003) suggest that researchers should report response rates and discuss how potential non-response error was handled because failure to do so brings the validity of survey findings into question. This is true because surveys that have high response rates are said to restore confidence in the findings (Wiseman 2003; Traugott \& Katosh 1979).

\section{DATA COLLECTION}

Demographically, South Africa's population is diverse in terms of culture, race, level of development and settlement (Mostert, Hofmeyr, Oosthuizen \& Van Zyl 1998). For this reason collecting data is a complex exercise in a country in which political opinions may have a different impact on some cultures, subcultures and regions from others.

There are likely to be conflicts of values and ethnic differences in relation to specific norms, attitudes, and cultural expectations in different geographical regions and settlements such as urban areas versus villages and in respondents with different educational backgrounds or socio-economic status. As Smith (1976) has long maintained, social scientists and researchers risk losing sight of other 
regional systems altogether in some cases, or assume them in others, as in the case where rural areas may be assumed to belong to a broader national category.

Unlike those involved in ethnographic and other qualitative studies where caution and site background are empirically considered and efforts made to study and understand the cultures of the regions under investigation, researchers who rely on quick facts may miss what Smith (1976) calls the 'cultural ecology' of the social systems being studied. Research organisations such as TNS Research Surveys, for example, which, in collecting data prefer to use electronic surveys and other innovative methodologies, for instance, online panel research, which save time and money, may spend little time studying cultural differences. This exposure to fallacies involving interpretations and language may result in bias.

In face-to-face interviews non-translated tools frequently yield unreliable outcomes and unreliable questionnaires produce meaningless results (www. evensenwebs.com/reliability.html). Surveys should be conducted in an unambiguous manner to minimise response errors and fieldworker bias or (mis)interpretation of measuring tools. For this to happen, evidence of measurement reliability should be revealed, especially in the cases of research organisations that use electronic methods that may be concealed from the subjects of the surveys.

At the centre of data collection is the question of the validity of what is collected or captured. Data that come from observations may be numbers, text, or even shapes, therefore it makes sense for researchers to be clear about what they actually aim to collect. In other words, 'data should capture the meaning of what the researcher is observing' (Durrheim 2002, p 46). But this also depends on the type of research the researcher is embarking upon. Different research studies are designed differently and each design is underpinned by particular philosophical paradigms or theories, for example, guiding the nature of surveys is a law-like positivist ontology underpinning objective quantitative designs. Consequently, the type of design the researcher chooses will determine which data collecting methods he or she is most likely to use.

Surveys follow particular methods of collecting data. For example, when collecting data researchers can interview respondents, conduct telephone interviews, or mail questionnaires to participants. Different organisations or researchers use those approaches that are convenient or most compatible with their established hypotheses and objectives.

Data collection in surveys is mostly undertaken through a primary data collection process that depends on the method employed. Fieldwork is most commonly a process in which researchers opt to undertake face-to-face interviews, but this is not to say that it is limited to this process. Fieldworkers are employed and trained to do telephonic interviews or to mail out questionnaires. 
Questionnaires are a popular means of collecting data, but are difficult to design and often require many rewrites before an acceptable one is produced. Some of the advantages include the fact that they can be used as methods in their own right, be posted, e-mailed or faxed, cover a large number of people or organisations and have wide geographic coverage, that they are relatively cheap, and that no prior arrangements are needed. But they can, on the other hand, be difficult to administer because of design problems and they have a pedigree of low response rate or response turnaround.

\section{CONCLUSION}

The conclusions and inferences drawn from many studies depend on the results, but the way the results are obtained remains a subject for further inquiry. Quantitative surveys strive for objective generalisation of results or claims that, prior to dissemination, are assumed to be true. The viability and authenticity of claims can be determined by the manner in which they are obtained (Cicourel 2007). There are many ways to obtain and interpret survey results and standards and guiding statistical analysis are used in doing so. Many pre-poll surveys may present results that are incompatible with results of the actual polls or may lack the 'ecological validity' vital to making accurate claims about situations. But there are other processes that should be considered before embarking on analysing data. One such process is data management.

Because the process of collecting data is not always 'clean' many survey organisations outsource or prepare the capacity for data management, that is, they prepare to capture, clean and process data before it can be analysed. Whether researchers collect data electronically or by the traditional face-to-face method questionnaires from the field always come with incomplete information or with errors overlooked by fieldworkers, mistakes that amount to errors that should always be taken into account.

Surveys that yield reliable results use various methods to make up for the errors encountered during data collection. Unfortunately, not all those who conduct surveys have the capacity to use data mining techniques to authenticate the results and failure to use such techniques contributes to variabilities and inconsistencies of results. By cleaning and preparing data researchers increase the validity of their claims and the objectivity of their generalisations. Recently, advanced computerised methods such as optical mark recognition have been applied to research surveys and test scoring procedures. These are scanning devices that can read carefully placed pencil marks on specially designed documents, and their use in census surveys, elections and other test-scoring exercises have proved to be accurate and to increase reliability (Frendberg 1993). 
The choice of analysis methods and the way certain indices are computed in surveys has an effect on the output results and interpretation. Specific analysis methods are underlined by the objectives and goals of the survey. Some methods have high psychometric properties in assessing degrees of correlation between variables, some assess the predictive abilities of some variables on other variables, and others simply describe the nature of data. The point is that to use analysis methods for purposes for which they are not intended affects the results.

\section{- REFERENCES -}

ACE. nd. Public Opinion Surveys and Exit Polls. Available at: aceproject.org/main/ english/lf/lfd08e.htm

Adcock, R \& D Collier. 2001. 'Measurement validity: a shared standard for qualitative and quantitative research'. The American Political Science Review 95(3).

Caplan, B. 2002. 'Sociotropes, systematic bias and political failure: reflections on the survey of Americans and economists on the economy'. Social Science Quarterly 83(2).

Cicourel, A V. 2007. 'A personal, retrospective view of ecological validity'. An Interdisciplinary Journal of Language 27(5-6), October.

Clausen, A R. 1968. 'Response Validity: Vote Report'. The Public Opinion Quarterly 32(4).

Crocker, L \& J Algina. 1986. Introduction to classical and modern testing theory. Orlando: Holt, Rinehart and Winston, Inc.

Cronje, F. 2009. An early forecast of South Africa's 2009 election results. Available at: <http:/ / p10.opennetworks.co.za/ sairr.org.za/sairr-today/news_item.2009$01-21.3170419646 />$

Crossen, C. 2006. 'Fiasco in the 1936 survey brought science to election polling'. The Wall Street Journal.

Denver, D, R Johns \& C Carman. 2009. 'Rejected ballot papers in the 2007 Scottish Parliament election: The voters' perspective'. British Politics 4(1).

Diebold, F X \& L Kilian. 2001. 'Measuring predictability: theory and macro-economic applications'. Journal of Applied Econometrics 16(6).

Durrheim, K. 2002. 'Research Design'. In M Terre Blanche \& K Durrheim (eds). Research in practice: applied method for the social sciences. Cape Town: University of Cape Town Press.

Evensen Web Design. 'Questionnaire Reliability'. Available at:<www.evensenwebs. com/reliability.html>

Exell, R H B. 2001. King Mongkut's University of Technology Thonburi. Available at: $<$ www.jgsee.kmutt.ac.th/exell/PracMath/ErrorAn.htm> 
Franklin, C. 2003. 'Polls, Election Outcomes and Sources of Error'. Paper presented at the annual meeting of the American Association for Public Opinion Research, Nashville, 16 August.

Frendberg, N Y. 1993. 'Scanning questionnaires efficiently'. Marketing Research $5(2)$.

GMI.2010.Marketresearchglossaryofterms. Availableat: $<$ www.marketresearchterms.com r.php>

Goliath. 2004. Bootstrap methods for developing predictive models. Available at: < goliath. ecnext.com/coms2 / gi_0199-3572940/Bootstrap-methods-for-developingpredictive.html>

Guy, R F, C E Edgley, I Arafat \& D E Allen.1987. Social Research Methods: puzzles and solutions. Massachusetts: Allyn and Bacon Inc.

Hernon, P \& C Schwartz. 2009. 'Reliability and validity'. Library and Information Sciences Research 31(2).

Idasa. 2006. Reporting on public opinion surveys. Available at: $<$ www.wordonthestreet. org.za>

Ipsos Markinor. 2010. Omnibus Offerings. Available at: brandsandbranding-online. co.za/images/brand_profiles/09_Profiles/Ipsos.pdf

Kane, M T. 2008. 'Terminology, emphasis, and utility in validation'. Educational Researcher 37(2).

Kimball, D C \& M Kropf. 2005. 'Ballot Design and Unrecorded Votes on Paper-Based Ballots'. Public Opinion Quarterly 69(4).

Lijphart, A. 1979. 'Religious vs. linguistic vs. class voting: The crucial experiment of comparing Belgium, Canada, South Africa, and Switzerland'. American Political Science Review 73.

Litwin, M. 1995. 'How to measure survey reliability and validity'. Survey Kit 7. Beverly Hills, CA: Sage Publication.

Lynn, P \& R Jowell. 1996. 'How might opinion polls be improved? The case for probability sampling'. Journal of the Royal Statistical Society 159(1).

Mattes, R, A Gouws, W James and H Kotze. 1994. IDASA National Election Survey, 1994. Available at: <sada.nrf.ac.za/ ahdetails.asp?catalognumber=0109>

Moskowitz, C S \& M S Pepe. 2004. 'Quantifying and comparing the predictive accuracy of continuous prognostic factors for binary outcomes'. Biostatistics $5(1)$.

Mobile Researcher. nd. Paper versus mobile data collection. Available at: <http:/ / community.populi.net/mobileresearcher/index.php/2010/03/ paper-versusmobile-data-collection/>

- nd. A breakthrough in research technology. Available at: <www.populi.net/ mobileresearcher/> 
Mostert W P, B E Hofmeyr, J S Oosthuizen \& J A Van Zyl. 1998. Demography: Textbook for the South African student. Pretoria: HSRC Publishers.

Mugo, F W. 2002. Sampling in Research. Available at: <www.indiana. edu/ educy520/sec5982/week_2/mugo02sampling.pdf>

Palmquist, M. 2005. Survey Research. Available at: <writing.colostate.edu/guides / research/survey/>

Parry, H J \& H M Crossely. 1950. 'Validity of Responses to Survey Questions'. Public Opinion Quarterly 14.

Pillay, U, B Roberts \& S Rule. 2006. South African Social Attitudes: changing times, diverse voices. Cape Town: HSRC Press.

Rivera M A. 2009. Election Resources on the Internet: the Republic of South Africa Electoral System. Available at: electionresources.org/za/system/

Rymarch, G K. Validity. Available at: <www.socialresearchmethods.net/tutorial / Rymarchk/rymar2.htm>

SABC News. 2009. Zuma laughs off Ipsos Markinor Poll. Available at: www. sabcnews.com/portal/site/SABCNews/menuitem.5c4f8fe7ee929f602ea1 2ea1674daeb9?vgnextoid=e790e8d5198bf110VgnVCM10000077d4ea9bRC RD\&vgnextfmt $=$ default\&channelPath $=$ Politics $+\% 3 \mathrm{E} \% 3 \mathrm{E}+$ Government

Schulz-Herzenberg, C. 2009. Survey projections for the 2009 elections - fact or fiction? Available at: <www.sabcnews.co.za/SABCnews.com/Documents / Projections.pdf>

Seekings, J. 1997. 'From the ballot box to the bookshelf: studies of the 1994 South African general election'. Journal of Contemporary South African Studies 15(2).

Smith, C A. 1976. Regional Analysis. New York: Academic Press.

Smith, T. 1987. 'The Art of Asking Questions 1936-1985'. Public Opinion Quarterly 51(4) Part 2.

South African Institute of Race Relations. 2009. SAIRR Today: An early forecast of South Africa's 2009 election results. Available at: <www.sairr.org.za/sairrtoday/news_item.2009-01-21.3170419646>

Southall, R. 1994. 'The South African elections of 1994: the remaking of a dominant party state'. The Journal of Modern African Studies 32(4).

Squire, P. 1988. 'Why the 1936 Literary Digest Poll failed'. The Public Opinion Quarterly 52(1).

Sullivan, T. 2009. 'Hutchison questions new poll'. Available at: <http: / / blogs. chron.com/texaspolitics/archives / 2009/11/hutchison_quest.html>

Sylvester, J. 2009. Opposition performance at the polls in 2009. Cape Town: Idasa.

Trochim, W M K. 2006. Measurement validity types. Available at: <www. socialresearchmethods.net $/ \mathrm{kb} /$ measval.php> 
Truman, D B. 1951. 'Some political variables for election surveys'. International Journal of Opinion and Attitude Research 5.

Traugott, M W \& J P Katosh. 1979. 'Response Validity in Surveys of Voting Behaviour'. Public Opinion Quarterly 43.

Weisberg, H F, J A Krosnick \& B D Bowen. 1996. An introduction to survey research, polling and data analysis. London: Sage.

Weissberg, R. 2001. 'Why Policymakers Should Ignore Public Opinion Polls'. Policy Analysis 402, 29 May.

White, C. 1992. Can the HSRC join in the future? Transformation 18.

Wiseman, F. 2003. 'On the Reporting of Response Rates in Extension Research'. Journal of Extension 41(3).

Worthen, B R, W R Borg \& K R White. 1993. Measurement \& evaluation in the schools. London: Longman.

- nd. Vocabulary Terms for Research in Psychology. Available at: <psychlab1. hanover.edu/Classes/Research/Terms.html>

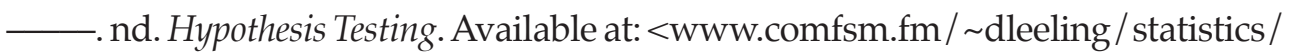
notes010.html>

- 2009. Oral presentations at PHASA 2009 on mHealth. Available at: <community. populi.net/mobileresearcher/index.php/2009/12/ oral-presentations-atphasa-2009-on-mhealth/> 